\title{
THE EFFECT OF THE FLORAL APPLICATION OF GIBBERELLIC ACID ON UNPOLLINATED INFLORESCENCES OF THE DATE PALM CULTIVAR ASSIANE (Phoenix dactylifera L.): A CASE STUDY OF FIGUIG OASIS, MOROCCO
}

\author{
Mourad Baba $^{1 *}$, Ibtissam Mzabri ${ }^{1}$, Jamal Mimouni ${ }^{2}$, Noureddine Kouddane ${ }^{1}$, Abdelbasset Berrichi ${ }^{1}$ \\ ${ }^{1}$ Laboratory for Improvement of Agricultural Production, Biotechnology and Environment, Faculty of Sciences of Oujda, University of Mohammed Ire, Oujda, Morocco \\ ${ }^{2}$ Territorial Department of Figuig, National Agency for the Development of Oasis and Argan Tree Areas, Erfoud, Morocco
}

Received - April 15, 2021; Revision - June 04, 2021; Accepted - June 22, 2021

Available Online - June 25, 2021

DOI: http://dx.doi.org/10.18006/2021.9(3).287.293

\begin{tabular}{l} 
KEYWORDS \\
Oasis of Figuig \\
Cultivar Assiane \\
Parthenocarpie \\
Fruit set \\
Gibberellic Acid \\
\hline
\end{tabular}

\begin{abstract}
The objective of the present study was to evaluate the effect of Gibberellic Acid in mitigate the phenomenon of parthenocarpy and improve the fruit set in the date palm cultivar Assiane at Figuig Oasis in Morocco. For this, four different concentrations of Gibberellic Acid (GA3) viz., 5, 50, 100, and $200 \mathrm{ppm}$ were applied on unpollinated inflorescences in two phases. The first dose of GA3 is applied at the time of spadices burst while the second one is applied after the seven days of the first one. The results obtained from the study showed that the application of gibberellic acid on unpollinated female inflorescences had a significant effect on the removal of parthenocarpy which resulting in the higher normal-looking fruits with normal seed and by promoting the maturity of parthenocarpic fruits. In the case of rate of thinning, the application of GA3 @ 5-100 ppm enhanced the flower drop, while the application at higher concentration i.e. $200 \mathrm{ppm}$ promotes the retention and development of flowers. Further, the analysis of the ripe fruits sugars content by high performance liquid chromatography (HPLC) suggests that the application of GA3 did not have any significant effect on the sugar content and these treatments are not significantly different from the fruits of pollinated flowers.
\end{abstract}

* Corresponding author

E-mail: m.baba.andzoa.dtf@gmail.com (Mourad Baba)

Peer review under responsibility of Journal of Experimental Biology and Agricultural Sciences.

Production and Hosting by Horizon Publisher India [HPI] (http://www.horizonpublisherindia.in/).

All rights reserved.
All the articles published by Journal of Experimental Biology and Agricultural Sciences are licensed under a Creative Commons Attribution-NonCommercial 4.0 International License Based on a work at www.jebas.org.

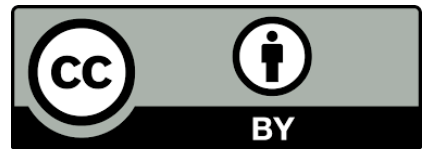




\section{Introduction}

The city of Figuig is the last territorial community located in the south of the Eastern region, around $400 \mathrm{~km}$ away from the Mediterranean and surrounded by the mountains and MoroccanAlgerian borders. The oasis of Figuig covers an area of 1882 hectares and has almost 234772 trees of date palm, which is distributed between the old palm grove and the extension areas (RNA, 2016). It encompasses a varietal diversity with a dominance of the Assiane variety which represents more than $51 \%$ of the total population, followed by the variety Boufegous (14\%), Khalt (14\%), Aziza Bouzid (6\%), Boufegous Gharas (5\%) and Mejhoul (2\%) (ANDZOA, 2012). In 1994, the closure of the Moroccan-Algerian border led to the isolation of the city causing a brutal reduction of its economic resources. Moreover, the oasis socio-economic situation was worsened by the negative effects of climate change, which was manifested mainly by the increasing frequency of the appearance of parthenocarpic fruits in the most dominant variety of the oasis. Since 2016, the rate of parthenocarpy in the Assiane variety has even exceeded $60 \%$.

The previous studies revealed that the phenomenon of parthenocarpic is constant, facultative, or accidental due to various factors including environmental or genetically. In the case of date palms, parthenocarpic dates (two to three developed carpels) resulting from the processing of unfertilized flowers are very fragile and have no commercial value as they rarely reach the stage of maturity (Zahid \& De Wet, 1999).

Phytohormones notably gibberellic acids (GA3) have been widely used to improve the fruit set rate and fruiting in several species. According to Shabaq \& Halala (2014), the application of GA3 (100, 125 mg.1-1) in combination with Naphthaleneacetic acid (50, 100 mg.1-1) gave the maximum value of most physical characteristics, fruit set, yield, and oil in olive trees. Similarly, work carried out by Kaidi et al. (2016) also suggested the impact of GA3 application on increasing the fruit set and yield of Citrus clementina in the Gharb region of Morocco, this study suggested that the impact of this hormone varied from year to year and is mainly depending on various parameters including the number and size of fruits. The objective of the present study was to evaluate the impact of GA3 application on the date palm fruit set rate and the intrinsic quality of dates in the Assiane variety at the Figuig oasis in Morocco.

\section{Materials and Methods}

\subsection{Study Area}

The oasis of Figuig in Morocco is characterized by a Mediterranean-Arid climate with a very hot summer, where the maximum average temperature is reported between 40 to $42^{\circ} \mathrm{C}$ during July and August. It is also characterized by a very cold winter where the minimum average temperature is $3^{\circ} \mathrm{C}$. The average annual rainfall is low $(122 \mathrm{~mm})$ and unevenly distributed over time (DPA, 2009).

The annual production of dates in Figuig was estimated at around 3600 tons/year, with a yield of $35.5 \mathrm{~kg} /$ foot (Elguerrouj, 2010). While in the case of individual variety, the production of the cultivar Assiane was exceeded 1900 tons which represents 54\% of the total production of dates. The price of dates of this cultivar varies from $25 \mathrm{Dh}$ to $35 \mathrm{Dh}$ per kilogram (DPA, 2009). This study was carried out at the farm level of the Aziza cooperative, located in the Tisser fine extension zone of the Figuig oasis in Morocco. The altitude and GPS coordinates of the Aziza farm are $860 \mathrm{~m}$ and $32.160442,-1.309530$ respectively.

\subsection{Plant material}

The plant material used in this study concerns the Assiane variety. It is a dominant variety in the Figuig oasis (Chafi, 2016). Its period of bloom occurs between February and the beginning of May and its date maturity starts around the end of June (Sedra, 2003).

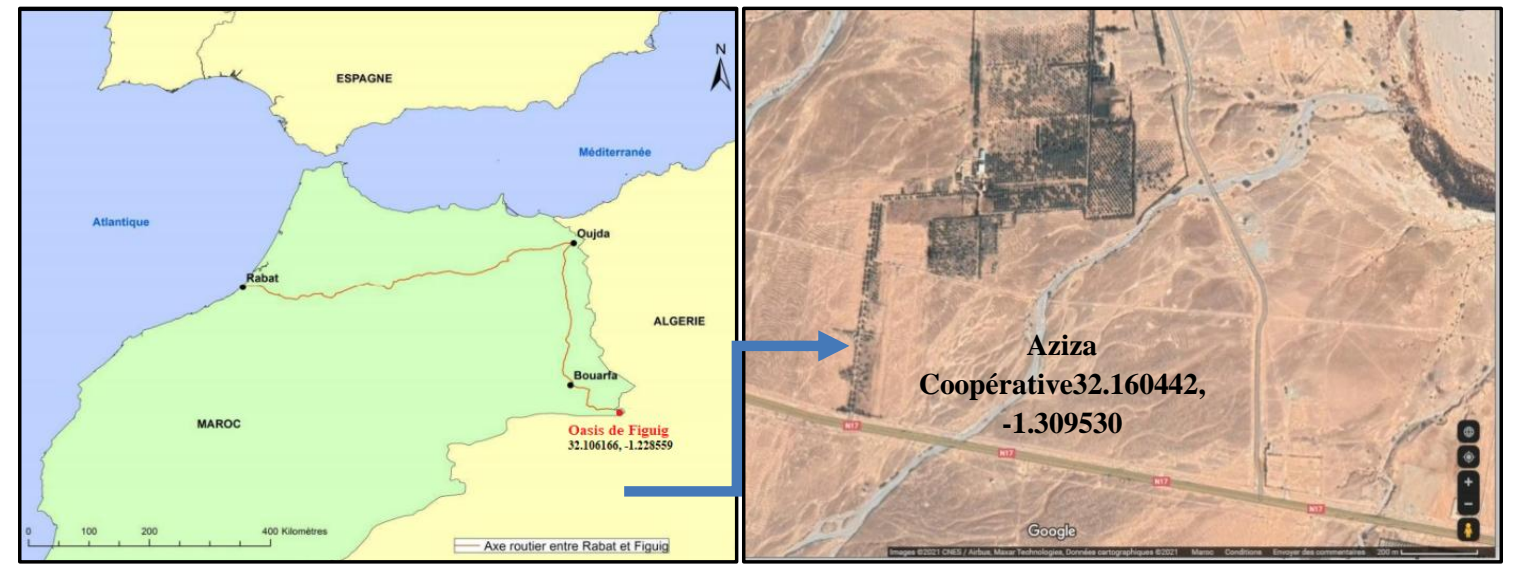

Figure 1 (A) Location of the Figuig Oasis; (B) Location of the Aziza Cooperative

Journal of Experimental Biology and Agricultural Sciences http://www.jebas.org 


\subsection{Imposed Treatment of GA3}

Four doses of Gibberellic Acid (GA3) viz., 5 ppm (T2), 50 ppm (T3), $100 \mathrm{ppm}$ (T4), and $200 \mathrm{ppm}$ (T5) was used to evaluate the impact of GA3 (Berelex 40sg, StéMarbar S.A, Lot n²70-933-54) application on Assiane variety parthenocarpy, improved fruit set and intrinsic quality of fruit. The control aspect of this experiment is the untreated and unpollinated inflorescence (T0), which was bagged with kraft paper. While for the treatment (T1), the inflorescence was not treated with GA3 and was pollinated traditionally. The inclusion of the inflorescence (T1) was only used to depict the normal circumstances under which the seed develops into fruit during the same period of the treatment of the experimental inflorescences.

\subsection{Test Conditions and Experimental Device}

This experiment was carried out in a completely randomized block design with three female plants (treatments), and each plant had six inflorescences (Figure 2). Before bursting, the spadices were bagged with kraft paper to prevent pollination. The first dose of GA3 is applied at the time of spadices burst while the second one is applied after the seven days of the first one. The bagging of the inflorescences treated with kraft paper was maintained for one month after the second treatment until the fruit set. the rate of parthenocarpy, and the rate of thinning were calculated according to the following formulas:

Rate of fruit set $(\%)=\frac{\text { Number of fruits tied }}{\text { Total number of flowers }} \times 100$

Rate of parthenocarpy $(\%)=\frac{\text { Number of parthenocarpic fruits }}{\text { Total number of flowers }} \times 100$

Rate of thinning $(\%)=\frac{\text { Number of follen flowers }}{\text { Total number of flowers }} \times 100$

\subsubsection{Production}

At harvest, the net weight of the bunch, the thinning rate as well as the number and weight of the fruits were determined per inflorescence.

\subsubsection{Morpho-metric and chemical characteristics of the fruits}

After harvesting the fruits on which the treatment has been imposed, were counted and categorized based on their maturity and presence or absence of the seed. Three categories have been thought to be found (figure 3). The first category is consisted of unripe fruits without seed or contains the abortifacient seed (a). The second category is constituted of ripe fruits without seed or contains abortifacient ones (b). On the contrary, the third category contains ripe fruits that have the normal seed (c) while the last category contains ripe fruit with natural pollination (d). For each category, a sample of 10 randomly selected fruits was measured (length, width) using a mechanical caliper and weighed via a

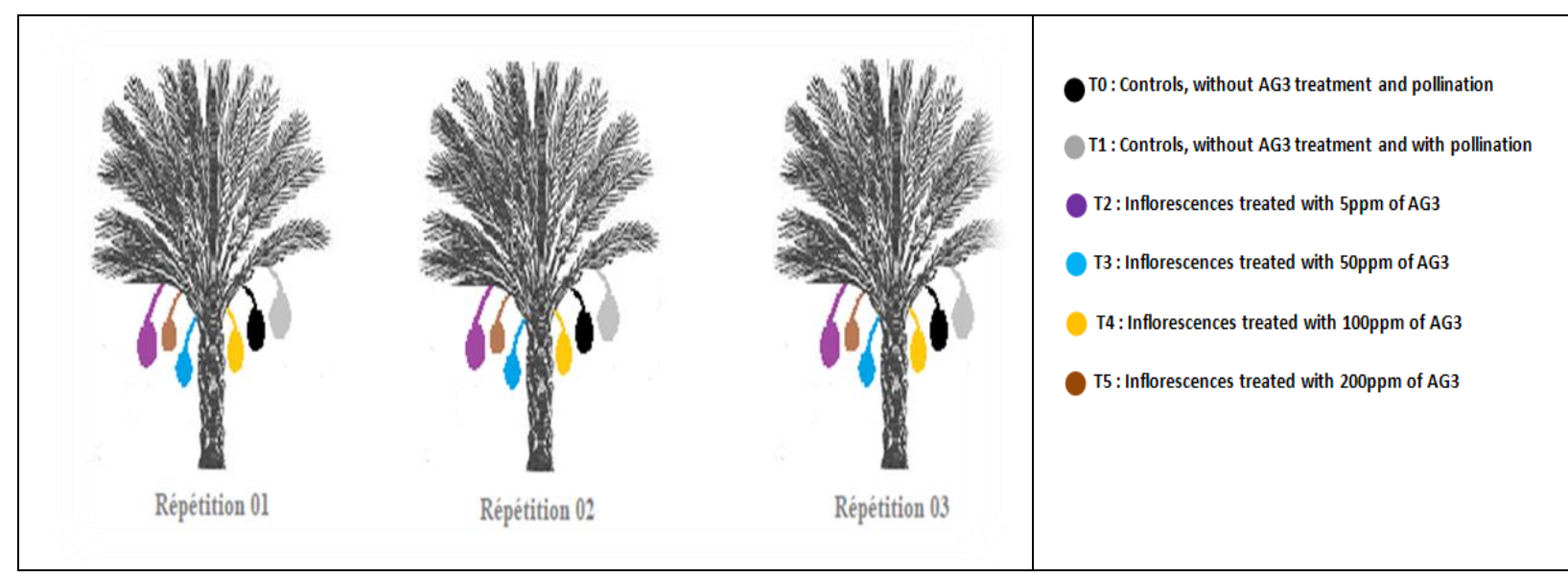

Figure 2 Experimental device for the application of GA3 on female feet of the Assiane variety

\subsection{Measured parameters}

\subsubsection{Fruit set, parthenocarpy, and thinning rates}

After the removal of the protective bags, per inflorescence rate of fruit set, parthenocarpy, and thinning were estimated; this calculation was based on a sample composed of 15 spikelets per inflorescence (5 spikelets from each upper, middle, and lower part of the inflorescence). The knotted fruits, parthenocarpic fruits, and fallen flowers in each spikelet were counted. The rate of fruit set, digital scale (WCX brand, accuracy of 0.1g) (Figure 3).

To determine the levels of sugars (fructose, glucose, maltose, and sucrose) in each category, a sample of 10 randomly selected fruits were crushed, homogenized, and analyzed using high-performance liquid chromatography (HPLC) (Lech, 2018). The analysis was conducted by solid-liquid extraction using water as the extraction solution, followed by filtration. The separation and identification of sugars were done by HPLC (Bekman M332) with a RID-type detector and an $\mathrm{NH} 2$ column. 


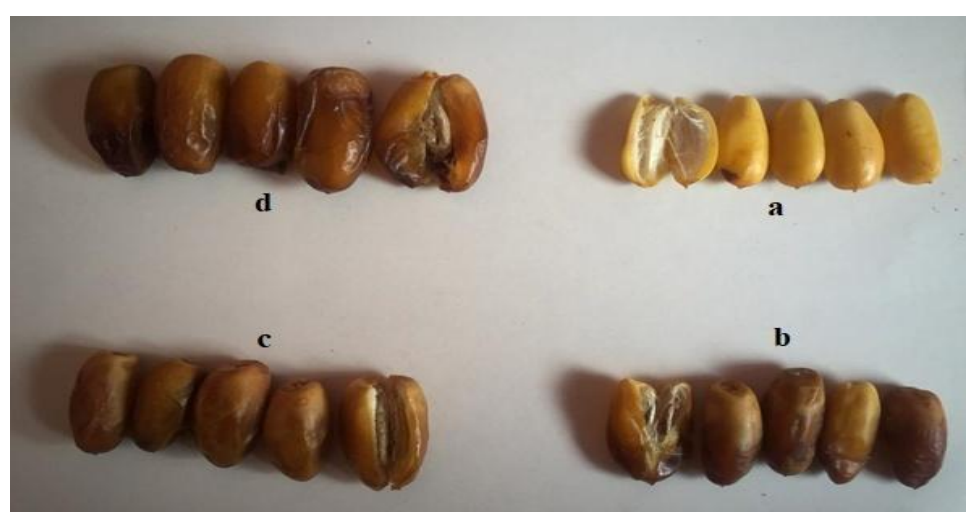

Figure 3 Different Categories of fruits treated with or without GA3: (a) Unripe fruit, without stone or containing an abortive stone, without pollination and treated with GA3; (b) Ripe fruit, without stone or containing an abortive stone, without pollination and treated with GA3; (c) Ripe fruit containing a stone, without pollination and treated with GA3 treatment; and (d) Ripe fruit containing a seed, with pollination and without GA3 treatment.

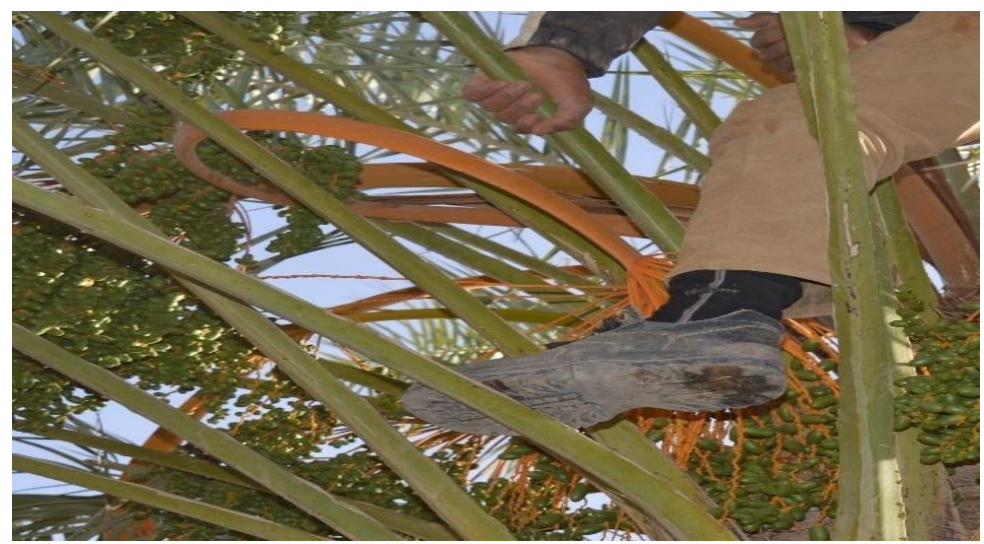

Figure 4 Deformation of the stems of inflorescences treated with GA3

\subsection{Statistical analysis}

The results were subjected to descriptive statistical analysis and analysis of variance (ANOVA), using the software "GraphPad Prism for Windows version 7" and the comparison of the means was made by Duncan's test at the $5 \%$ probability threshold.

\section{Results and Discussion}

\subsection{Fruit set, parthenocarpy, and thinning rates}

Results of the current study suggested that under sex perimental conditions i.e. untreated and unpollinated inflorescence (T0 control), the rate of fruit set, parthenocarpy, and thinning was reported $0 \%, 89.21 \%$, and $13.79 \%$ respectively. While the natural pollination conditions (T1) had a fruit set rate of $30.95 \%$, a parthenocarpy rate of $27.56 \%$, and a thinning rate of $41.5 \%$.

As per the results given in figure 5, the increasing doses of GA3 on unpollinated female inflorescences of the Assiane variety resulted in an average fruit set rate of $10.14 \%$. These results were confirmed by the analysis of variance which detected a statistically significant difference between treatments $(\mathrm{p}=0.021)$. Furthermore, the analysis of variance classified the treatments into three groups viz., the best treatment is the $\mathrm{T} 1$, followed by the treatment $\mathrm{T} 5$ of the highest dose of GA3 (200ppm) and then the treatments T2, T3, and $\mathrm{T} 4$ which represent no significant difference from the T0 control.

In the case of parthenocarpy, the applied statistical analysis showed significant differences $(\mathrm{p}=0.042)$, which divided the used treatments into two groups, viz., group 1 had only treatment T0 (control) which had the highest rate of parthenocarpy $(86.21 \%$ ) while the group 2 have remaining five treatments (T1, T2, T3, T4, and T5). Application of GA3 had a significant effect on mitigating the effect of parthenocarpy and the highest dose applied of this hormone improved the fruiting rate by $15.95 \%$. In a very exceptional way, in the absence of pollination, GA3 favored the development of a category of fruits containing a normal-looking seed. However, it should be noted that the results obtained were accompanied by a deformation of the stems of the inflorescences treated with GA3 (Figure 4). 


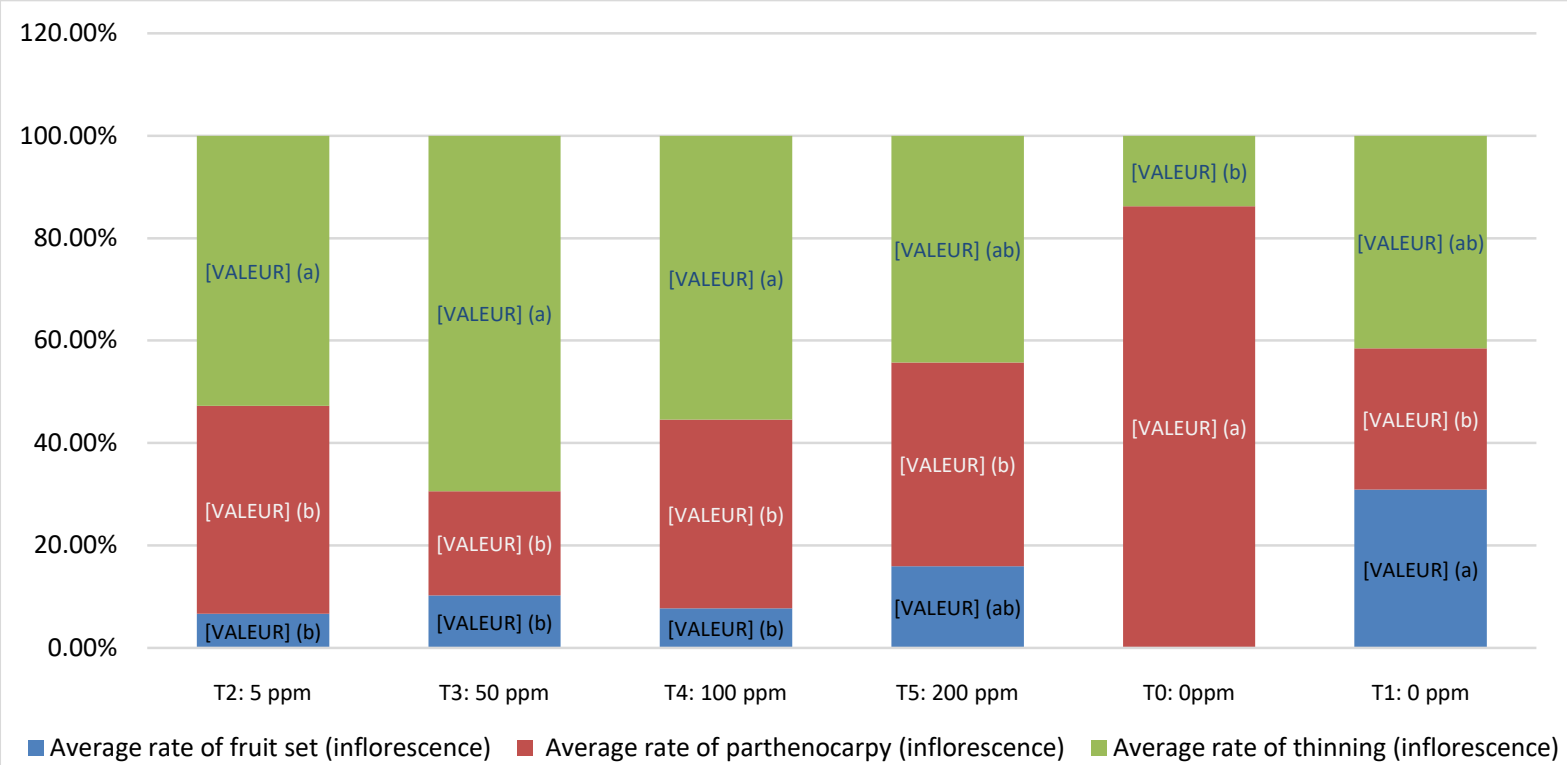

Figure 5 Effects of increasing doses of GA3 on fruit set, parthenocarpy, and thinning rates on unpollinated plants of the Assiane variety of date palm.

Concerning the thinning rate, statistical analysis of a 5\% probability threshold showed a significant difference between the parameters. Results of the study revealed the highest thinning rate in treatment $\mathrm{T} 2, \mathrm{~T} 3$, and $\mathrm{T} 4$ treatments, this was followed by the treatments $\mathrm{T} 1, \mathrm{~T} 5$, and $\mathrm{T} 0$ respectively (figure 5). Based on the results of this study, it can be concluded that lower doses of GA3 have a negative effect and increased flower fall while application at high doses favored their retention. These results are in agreement with the findings of PNTTA (2002) those who reported that the application of GA3 (10ppm) at a low rate (10ppm) played a pollinicidal role and caused flower fall in grapes, whereas the application of GA3 doses of 20 to $40 \mathrm{ppm}$ favored berry growth through the formation of larger grapes berries.

\subsection{Production}

At harvest, the fruit count of inflorescences treated with GA3 showed that the percentage of average ripe fruit was $1.08 \%$ per inflorescences and the majority of the set fruit was of category $b$, ranging from $78 \%$ to $100 \%$ (table 1). The difference between the fruit set rate was calculated two times, the first count was carried out one month after pollination while the second count was carried out at the time of harvesting and this difference rate was $89.35 \%$. Similarly, the flower drop after fruit set was also noticed by Saavedra (1979), when GA3 has been applied at the doses of 100 to $1600 \mathrm{ppm}$ to Annona cherimola Mill trees during flowering.
Thus, GA3 favored the ripening of parthenocarpic fruits and allowed the development of unfertilized flowers into normallooking fruit having normal seeds. These results are similar to those obtained by the application of GA3 on the cultivars Deglet Nour, Kentichi, and Menakher (Ben Abdallah \& Lepoivre, 2000).

\subsection{Morpho-metric and chemical characteristics of the fruits}

Results presented in table 2 suggested that the applied doses of GA3 did not improve the date's size. However, there was a slight difference between the fruits in category (c) and the treatment $\mathrm{T} 1$. These fruits are less than $0.4 \mathrm{~cm}$ in length, less than $0.11 \mathrm{~cm}$ in diameter, and less than $1.5 \mathrm{~g}$ in weight. This finding is probably due to a large number of parthenocarpic fruits in the treated inflorescences compared to treatment $\mathrm{T} 1$.

The effect of the increasing doses of GA3 on the chemical composition of dates, especially in the case of sugars, the parthenocarpic fruits $(5.1, \%$ and $7.2 \%)$ were poor in the concentration of fructose and glucose, as compared to the GA3 treated fruits $(34.5 \%$ and $37.3 \%)$. While this fructose and glucose value was reported $29.5 \%$ and $34.8 \%$ respectively for category (b). However, category (c) has a similar fructose level to the treatment (T1) except for slight increases in the level of glucose (1\%). Furthermore, maltose and sucrose levels remained unchanged for all four fruit categories $(\leq 0.5 \%)$. These results are in agreement with the results of Mohammed et al. (1983) that identified the characteristics of 50 varieties from Iraq. 
Table 1 Effect of GA3 doses on unpollinated female inflorescences of the date palm cultivar Assiane in the Figuig oasis

\begin{tabular}{|c|c|c|c|c|c|c|}
\hline \multirow{2}{*}{ ObservedCriteria (Medium) } & \multicolumn{2}{|c|}{ Controls } & \multicolumn{4}{|c|}{ GA3 concentration in ppm } \\
\hline & T0 & $\mathrm{T} 1$ & $\mathrm{~T} 2$ & $\mathrm{~T} 3$ & $\mathrm{~T} 4$ & T5 \\
\hline Weight Net Inflorescence (kg) & 12.35 & 8.99 & 7.58 & 0.916 & 7.99 & 7.68 \\
\hline Fallen flowers & 1653 & 1519 & 1983 & 2600 & 1476 & 2250 \\
\hline Number (a) & 5336 & 624 & 3516 & 112 & 3268 & 3618 \\
\hline Weight $(\mathrm{Kg}):(a)$ & 11.51 & 1.83 & 7.05 & 0.28 & 7.42 & 5.80 \\
\hline Number: (b) & 0 & 0 & 19 & 74 & 55 & 25 \\
\hline Weight $(\mathrm{Kg}):(\mathrm{b})$ & 0 & 0 & 0.072 & 0.261 & 0.021 & 0.102 \\
\hline Number: (c) & 0 & 883 & 4 & 5 & 0 & 7 \\
\hline Weight $(\mathrm{Kg}):(\mathrm{c})$ & 0 & 6.424 & 0.021 & 0.022 & 0 & 0.038 \\
\hline
\end{tabular}

Here category (a): Unripe fruit, without seed or containing an abortive seed, without pollination, and GA3 treated; category (b): Ripe fruit, without seed or containing an abortive seed, without pollination and GA3 treated; category (c): Ripe fruit containing a seed, without pollination and GA3 treated.

Table 2 Effect of GA3 on the morpho-metric-chemical characteristics of the fruits of the date palm cultivar Assiane in the Oasis of Figuig

\begin{tabular}{|ccccccccc}
\hline $\begin{array}{c}\text { Category of } \\
\text { fruit }\end{array}$ & \multicolumn{2}{c}{ Morpho-metric characteristics } & \multicolumn{3}{c|}{ Chemical characteristics (HPLC) (g/100 g) } \\
\hline (a) & 3.1 & 1.04 & 25 & 5.1 & 7.2 & $\leq 0.5$ & $\leq 0.5$ \\
\hline (b) & 3.56 & 1.1 & 35 & 29.5 & 34.8 & $\leq 0.5$ & $\leq 0.5$ \\
\hline (c) & 3.48 & 1.78 & 70 & 34.5 & 38.3 & $\leq 0.5$ & $\leq 0.5$ \\
\hline (d) & 3.9 & 1.9 & 85 & 34.5 & 37.3 & $\leq 0.5$ & $\leq 0.5$ \\
\hline
\end{tabular}

Here category (a) Unripe fruit, without seed or containing an abortive seed, without pollination, with GA3 treated inflorescence; Category (b) Ripe fruit, without seed or containing an abortive seed, without pollination and with GA3 treated inflorescence; category (c) Ripe fruit containing seed, without pollination and with GA3 treated inflorescence; category (d): Ripe fruit containing seed, with pollination and without GA3 treatment.

\section{Conclusion}

In conclusion, the results of the current study showed that the application of gibberellic acid on unpollinated female inflorescences of the cultivar Assiane has a significant effect on mitigating the parthenocarpy. Therefore, a significant improvement in the fruit set has been accomplished by encouraging the development of unfertilized flowers into normallooking fruits having normal-looking seeds and promoting the maturity of parthenocarpic fruits. Indeed, at maturity, their sugar content did not show significant variations compared to fruits of pollinated flowers. Regarding the rate of thinning, application of 5-100ppm GA3 caused flower drop, while application of a high dose of 200ppm promoted the retention and development of flowers.

Certainly, GA3 can be considered as a beneficial hormone to control parthenocarpy in the cultivar Assiane and the application of
$200 \mathrm{ppm}$ of this hormone, in combination with traditional pollination, will have a significant effect on yield. However, the rate of fruit set induced at $200 \mathrm{ppm}$ remains low, taking into account the cost of labor and depreciation of the equipment needed to treat the inflorescences. This study has therefore opened up an encouraging avenue of research to pursue in future years by using a high dose of GA3 on several occasions.

\section{Acknowledgement}

The authors would like to express their gratitude to the owners of the Aziza cooperative for granting permission to conduct this study on their farm.

\section{Conflict of Interest}

The authors of this article have no conflict of interest to declare. 


\section{References}

ANDZOA (2012) Study concerning the conduct of characterization studies of the palm groves forming the basis for the constitution of the Economic Interest Grouping - lot $n^{\circ} 1$ Engineering, Training, Studies and Development design office.

Ben Abdallah A, Lepoivre P (2000) Production de fruits et d'embryons diploïdes par traitement à l'acidite gibbérellique des inflorescences femelles non pollinisées chez le palmier dattier (Phoenix dactylifera L.). Cahiers Agricultures 9(6): 467-473.

Chafi A (2016) Study of the regeneration by rejection and pomology of some varieties of dates from the date palm of the Figuig oasis. Ph.D. thesis submitted to the Faculty of Sciences, Mohammed Premier University, Oujda.

DPA (Provincial Direction of Agriculture of Figuig) (2009) Intervention strategy of the DPA of Figuig, Ed. Ministry of Agriculture, Pp. 25.

Elguerrouj M (2010) Physicochemical study and evaluation of dates of two varieties of the Figuig oasis (Assiane and Aziza Bouzid). Ph.D. thesis submitted to the Faculty of Sciences, Mohammed V University, Rabat.

Kaidi I, Messaoudi L, Messaoudi Z, Fagroud M, Aithoussa A, Razine M (2016) Improving the efficacy of gibberellic acid to increase fruit set and yield of clementines in the Gharb region of Morocco. International Journal of Engineering Science Invention 5 (3): 72-77.
Lech K (2018) High Performance Liquid Chromatography (HPLC). The Encyclopedia of Archaeological Sciences, Pp. 1-7.

Mohammed S, Shabana HR, Mawlod EA (1983) Evaluation and identification of Iraqi date cultivars: fruit characteristics of fifty cultivars. Date palm Journal 2(1): 27-55.

PNTTA (National Program for Technology Transfer in Agriculture) (2002) The quality of table grapes. Effect of certain cultivation practices. Monthly Bulletin, Pp. 90. 2.

RNA (National Registry of Agriculture) (2016) Number of producers and date palm area by province. Ministry of Agriculture, Maritime Fishing, Rural Development, Water and Forestry. Morocco.

Saavedra E (1979) Set and growth of Annona cherimola Mill. fruit obtained by hand-pollination and chemical treatments.

Sedra MH (2003) Date palm as a basis of oases development in Morocco: agricultural technic and oases creation. INRA-Edition. Morocco.

Shabaq MN, Halala KA (2014) Effect of foliar application of GA3 and NAA for reducing alternate bearing of olive trees (Olea europaea L. cv. Ashrasie). IOSR Journal of Agriculture and Veterinary Science 7(1): 8-12.

Zaid A, De Wet PF (1999) Pollination and bunch management. Date palm cultivation. FAO, Roma (Italia). 